\title{
The Influence of the Particle Size on the Adhesion Between Ceramic Particles and Metal Matrix in MMC Composites
}

\author{
Dariusz M. Jarzabek, Marcin Chmielewski, Judyta Dulnik, and Agata Strojny-Nedza
}

\author{
(Submitted April 27, 2016; in revised form April 27, 2016; published online May 10, 2016)
}

\begin{abstract}
This study investigated the influence of the particle size on the adhesion force between ceramic particles and metal matrix in ceramic-reinforced metal matrix composites. The $\mathrm{Cu}-\mathrm{Al}_{2} \mathrm{O}_{3}$ composites with 5 vol.\% of ceramic phase were prepared by a powder metallurgy process. Alumina oxide powder as an electrocorundum $\left(\mathrm{Al}_{2} \mathrm{O}_{3}\right)$ powder with different particle sizes, i.e., fine powder $<3 \mu \mathrm{m}$ and coarse powder of $180 \mu \mathrm{m}$ was used as a reinforcement. Microstructural investigations included analyses using scanning electron microscopy with an integrated EDS microanalysis system and transmission microscopy. In order to measure the adhesion force (interface strength), we prepared the microwires made of the investigated materials and carried out the experiments with the use of the self-made tensile tester. We have observed that the interface strength is higher for the sample with coarse particles and is equal to $74 \pm 4 \mathrm{MPa}$ and it is equal to $68 \pm 3$ MPa for the sample with fine ceramic particles.
\end{abstract}

Keywords adhesion, interface strength, metal matrix composites, nanocomposites, tensile test

\section{Introduction}

Metal-ceramic composites (MMCs) combine properties of metal and ceramic materials and provide improved performance compared to their constituent phases. Their properties can be tailored to targeted applications by varying the volume fractions and the properties of the matrix as well as the type, shape, size, orientation, and distribution of the reinforcement and by controlling the reinforcement/matrix adhesion level (Ref 1, 2). While designing composites, one must take into account a number of factors that may substantially affect the quality of the final material. Generally, the main factor determining the material properties of hot-pressed composites is the selection of appropriate process parameters, like temperature, pressure, process atmosphere, heating/cooling rate, etc. (Ref 3-5). However, other factors include mutual solubility of components of the composite, the wettability of ceramics by liquid metals, thermal residual stress generated in a given material as a result of differences in thermal and mechanical properties of metals and ceramics or geometric distribution of the reinforcing phase in the matrix of composites (Ref 6). Also the homogeneity of

This article is an invited submission to JMEP selected from presentations at the Symposium "Metal-Matrix Composites," belonging to the topic "Composite and Hybrid Materials" at the European Congress and Exhibition on Advanced Materials and Processes (EUROMAT 2015), held on September 20-24, 2015, in Warsaw, Poland, and has been expanded from the original presentation.

Dariusz M. Jarzabek and Judyta Dulnik, Institute of Fundamental Technological Research, Warsaw, Poland; and Marcin Chmielewski and Agata Strojny-Nedza, Institute of Electronic Materials Technology, Warsaw, Poland. Contact e-mail: djarz@ippt.pan.pl. composite materials plays a crucial role in shaping their ultimate properties that determine their potential application in the industry.

One of the fundamental issues in the field of metal-ceramic bonding is the formation of matrix-reinforcement interface (Ref 7). The structure of the interface strongly depends on the factors mention above. Apart from the conditions of the manufacturing process such as temperature, pressure, time, and atmosphere, to the group of the most important factors which create the interface properties belong also the amount, form, shape, dimensions, and distribution homogeneity of the reinforcement. Knowing that the type of interface is one of dominant factors determining the properties of the composite, $t$ is plausible to assume that by controlling the interface formation process we may influence on the overall properties of the composite and, consequently, obtain a composite with desired ones.

In the case of metal-ceramic composite materials, various types of bonding between these two phases are possible. One can distinguish the mechanical, adhesive, diffusive, or reactive bonding (Ref 8,9). Different formation mechanisms, different quality and durability, which are inextricably linked with the interaction of the composite's components, are typical of each bonding.

Copper matrix composites with different ceramic reinforcements ( $\mathrm{AlN}, \mathrm{SiC}, \mathrm{C}, \mathrm{Al}_{2} \mathrm{O}_{3}$ ) are extensively used in aerospace industry in products that are subjected to severe thermal and mechanical loadings such as rocket thrusters and components in aircraft engines. Copper-alumina composites have numerous advantages. This material is used where high thermal conductivity, high absorption, and dissipation of heat and good frictional wear resistance are required. However, poor adhesion to widely used reinforcements, chemical reactions at interfaces, and quick oxidization of $\mathrm{Cu}$ can create serious problems with the formation of the strong bonds at the interface between composite components (Ref 10,11). Due to these properties, copper-alumina composites are widely employed as resistance welding electrodes, lead frames, accelerators, and electrical contacts. 
The properties of copper-alumina composites depend on a number of factors, including the content, shape, and distribution of the ceramic phase, their production method, as well as conditions under which they are obtained. The main disadvantages of composites with a low content of aluminum oxide particles include residual porosity and high internal stress generated because of differences between ceramics and metals which influence the properties of these materials. Another particularly crucial aspect is the production of an isotropic composite material, in which good metal-ceramic bonding will be obtained, without the third phase of the so-called nonstoichiometric compounds (spinels and oxides), which can significantly reduce the basic properties of these composites, including thermal conductivity. It has to also be stressed that pores are present in the area of the ceramic phase.

Therefore, the purpose of this paper is to describe the influence of the size of the reinforcing particles on the adhesion force between the ceramic particles and the metal matrix in MMCs. It is measured by the method developed and described in Ref 12. Basically, the adhesion force is measured by tension of the microwires in which the interesting interface is exposed. It is also possible to estimate the contact area by scanning electron microscope (SEM) imaging and to determine the interface strength. Our results indicate that the size of the reinforcement particles has an influence on the mechanical properties of the interface.

\section{Experimental}

In the present work, the copper powder (Sigma Aldrich, $99.9 \%$ purity) with granulation $10 \mu \mathrm{m}$ and the BET specific surface area of $0.61 \mathrm{~m}^{2} / \mathrm{g}$ was used as a metal matrix. Alumina
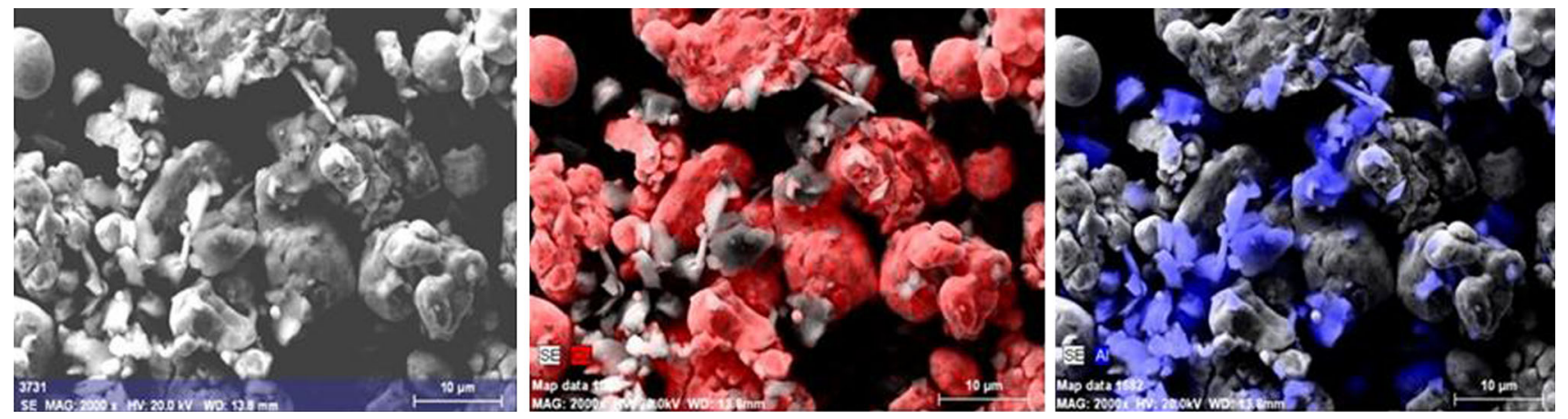

Fig. 1 The morphology (SEM) of powders and the surface distribution of elements (EDS) in composite mixtures after the mixing process for $\mathrm{Cu}-5$ vol. $\% \mathrm{Al}_{2} \mathrm{O}_{3}$ fine: red-copper, blue- $\mathrm{Al}_{2} \mathrm{O}_{3}$ (Color figure online)

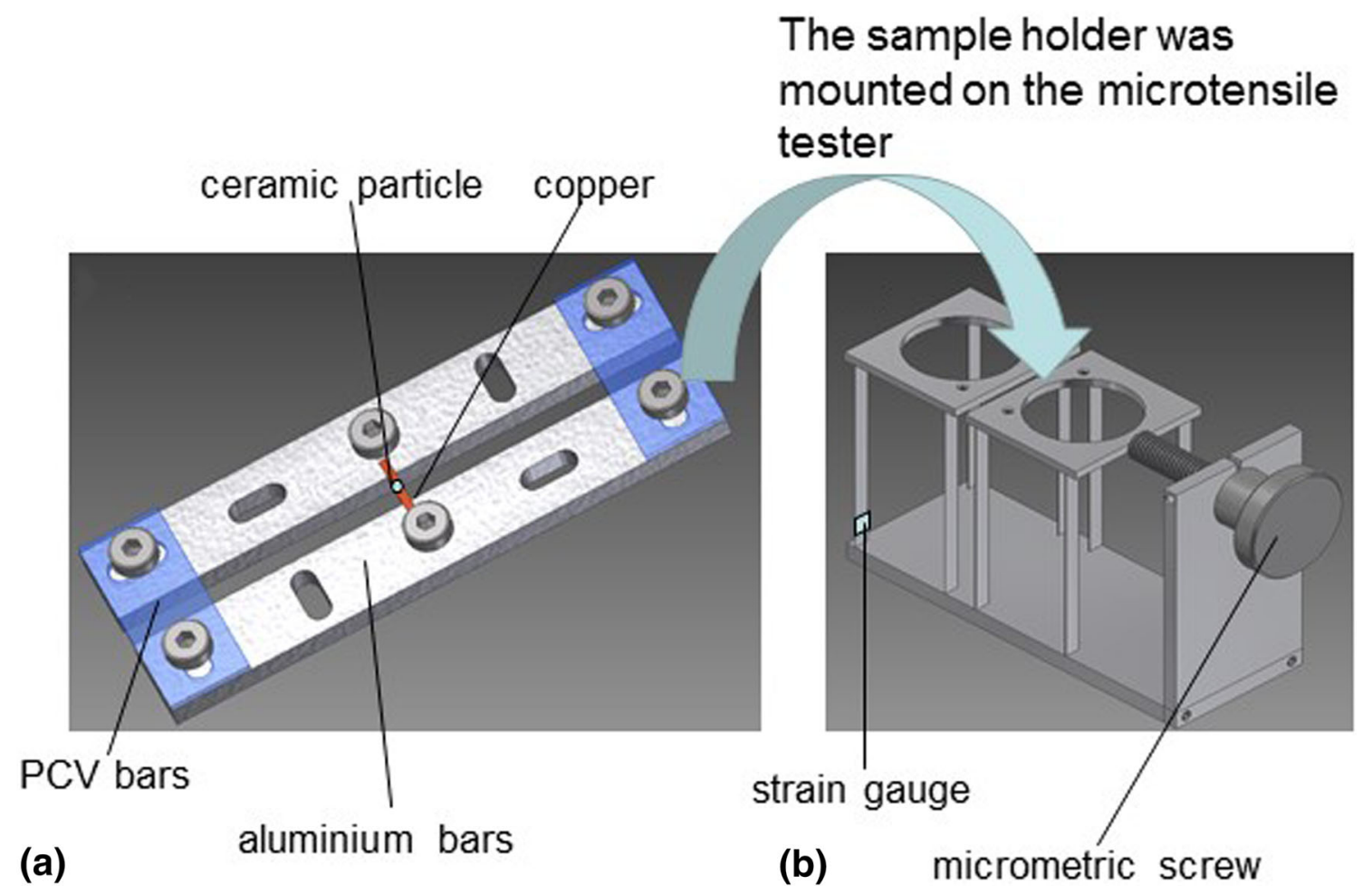

Fig. 2 The measurement setup. (a) Sample holder; (b) microtensile tester 
oxide powder as an electrocorundum $\left(\mathrm{Al}_{2} \mathrm{O}_{3}\right)$ powder with different particle sizes, i.e., fine powder $<3 \mu \mathrm{m}$ and coarse powder of $180 \mu \mathrm{m}$ (Polish company KOS, 99\% purity) was used as a reinforcement. The $\mathrm{Cu}-\mathrm{Al}_{2} \mathrm{O}_{3}$ composites with 5 vol.\% of ceramic phase were prepared by a powder metallurgy process. The powder mixtures were obtained in a mechanical mixing process using a planetary ball mill (Pulverisette 6 , Fritsch) with tungsten carbide balls $(\varnothing 5 \mathrm{~mm})$. The mixing process was conducted in the $\mathrm{N}_{2}$ atmosphere with the rotation speed of $200 \mathrm{rpm}$ and the time of mixing was $6 \mathrm{~h}$. Ballto-power ratio (BPR) was approximately 5:1. Presented mixing conditions were selected after the preliminary tests described in paper (Ref 13). The morphology of the obtained powder mixture $\mathrm{Cu}+5$ vol. $\% \mathrm{Al}_{2} \mathrm{O}_{3}$ fine $(3 \mu \mathrm{m})$ is presented in Fig. 1.

The $\mathrm{Cu}-\mathrm{Al}_{2} \mathrm{O}_{3}$ powder mixtures were placed in a graphite die and then sintered. The process of the sintering was conducted in an Astro Thermal Technology press in the $\mathrm{Ar}$ atmosphere at $1050{ }^{\circ} \mathrm{C}$ under pressure of $30 \mathrm{MPa}$. The samples
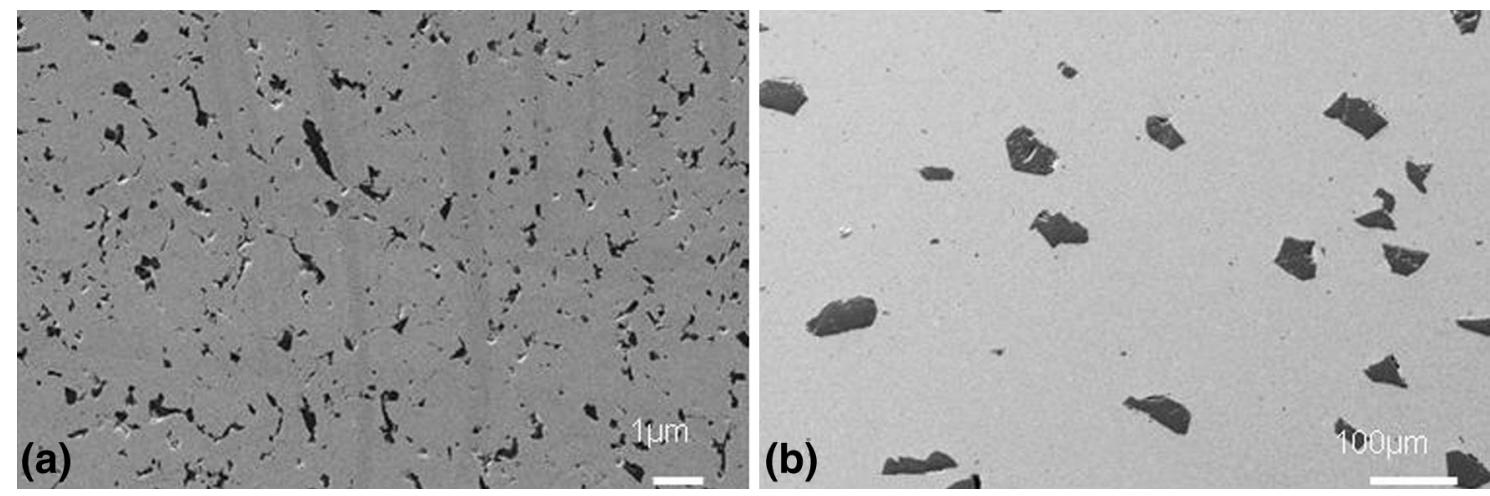

Fig. 3 SEM micrographs of the copper matrix composites with: (a) $\mathrm{Al}_{2} \mathrm{O}_{3}$ fine $(3 \mu \mathrm{m})$ and (b) $\mathrm{Al}_{2} \mathrm{O}_{3}$ coarse $(180 \mu \mathrm{m})$
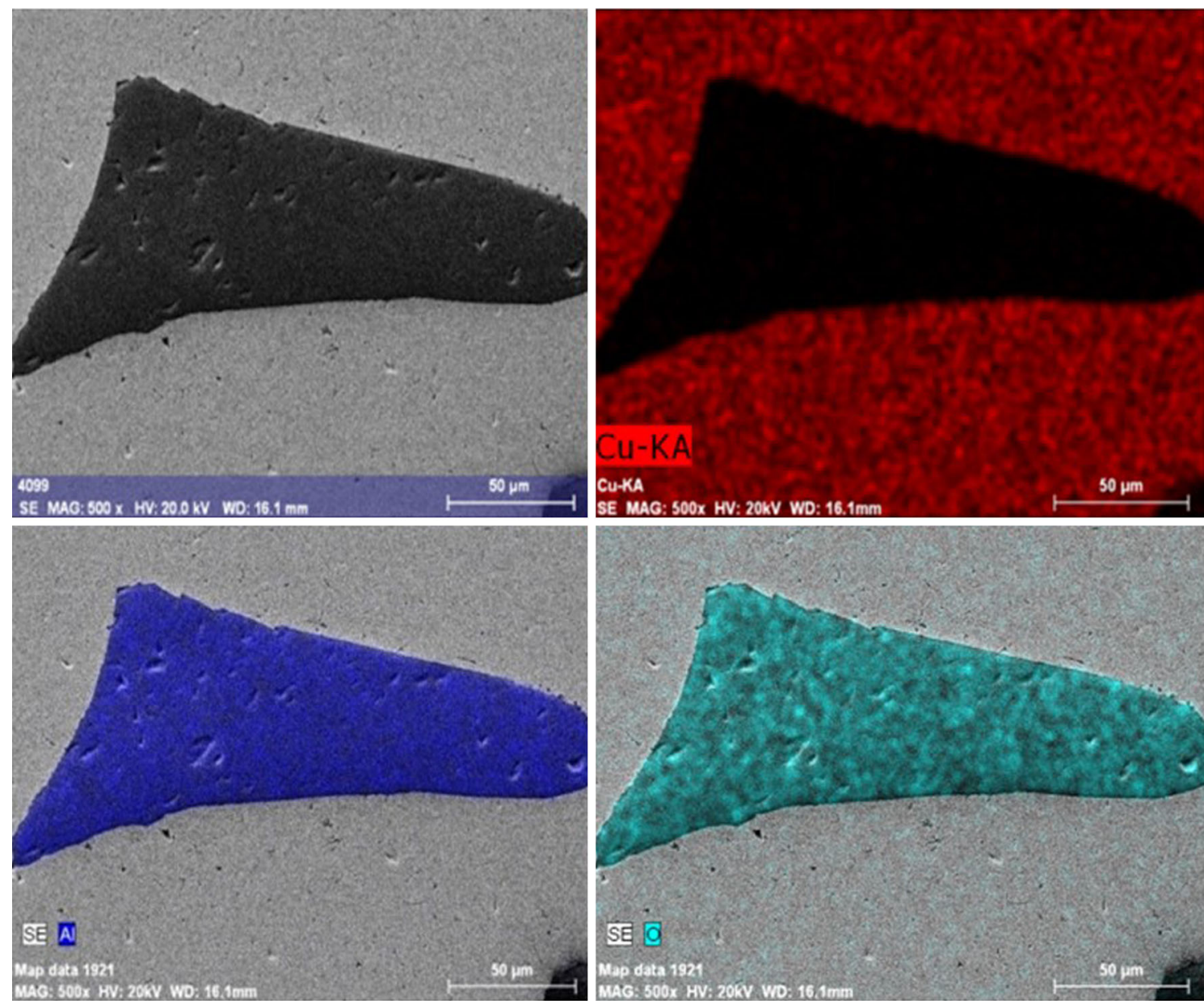

Fig. $4 \mathrm{SEM} / \mathrm{EDS}$ maps of distribution of element on the surface for $\mathrm{Cu}-\mathrm{Al}_{2} \mathrm{O}_{3}$ coarse; red — copper phase, blue - aluminium, and green — oxygen (Color figure online) 

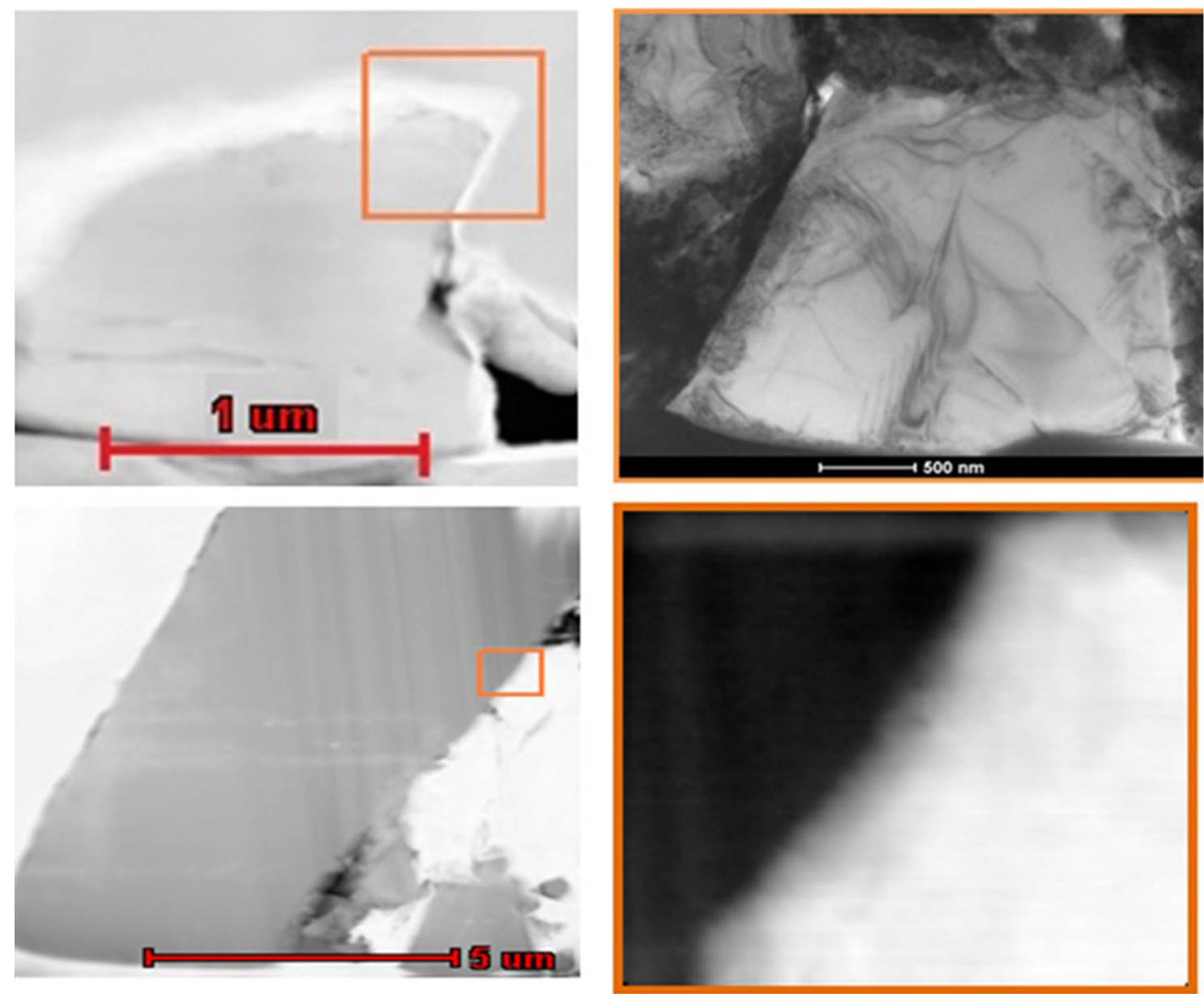

Fig. 5 TEM micrographs of composites: (a) $\mathrm{Cu}-\mathrm{Al}_{2} \mathrm{O}_{3}$ fine $(3 \mu \mathrm{m})$ and (b) $\mathrm{Cu}-\mathrm{Al}_{2} \mathrm{O}_{3}$ coarse $(180 \mu \mathrm{m})$

were held at this temperature for $30 \mathrm{~min}$ and then cooled naturally to room temperature in the furnace before they were removed.

Next, the samples were mechanically cut, grounded, and polished. Microstructural investigations included analyses using scanning electron microscopy (SEM, Auriga CrossBeam Workstation/Zeiss) with an integrated EDS microanalysis system and transmission microscopy (TEM, Tecnai G2 F20). The density of the obtained composites was measured according to the Archimedes method. The theoretical density was calculated on the basis of the densities of $\mathrm{Al}_{2} \mathrm{O}_{3}$ $\left(\rho_{\mathrm{Al}_{2} \mathrm{O}_{3}}=3.97 \mathrm{~g} / \mathrm{cm}^{3}\right)$ and copper $\left(\rho_{\mathrm{Cu}}=8.97 \mathrm{~g} / \mathrm{cm}^{3}\right)$. Hardness (HV1) was tested by Durascan 10/Emcotest with a Vickers diamond indenter using a load of $9.81 \mathrm{~N}$ applied for $10 \mathrm{~s}$. The hardness results were averaged over 5 indentations per specimen. The applied load was matched to the surface of mark to cover both the components of composite in a single measurement. In this case, we obtained the averaged response of the materials adequate to the content of $\mathrm{Cu}$ and $\mathrm{Al}_{2} \mathrm{O}_{3}$.

Subsequently, the precise wire saw was used to cut rods from the investigated materials. The rods were then put on the specially designed holder (Fig. 2a) and accurately electroetched. $40 \%$ phosphoric acid was used as an etching solution. The precise electro-etching technique was applied due to the fact that alumina particles do not conduct electricity. The wires were etched until it was observed that the wire did not conduct electricity. It was then assumed that there had been the part of the wire in which the interface had been fully exposed. The wires were also checked with optical or scanning electron microscope. If the sample conducted electricity, then the electro-etching was continued and the conductivity was tested again after a few seconds. Due to the etching, the microwires with exposed interface between copper and ceramic particle were produced.

The sample's holder consists of two bars made of aluminium, to which the rod is clamped, and two connection bars made of PCV. PCV does not conduct electricity, and therefore, it is easier to measure the sample's conductivity. When the microwire was produced, then the holder was carefully mounted on the self-made microtensile tester (Fig. 2b). The microtensile tester consists of two stages, to which two aluminum bars are screwed. After the sample's holder was mounted, the PCV bars were removed and it was possible to tensile the microwire. Concerning the tensile tester's sensitivity to very low loads, one of the stages is mounted at the end of four thin $(0.2 \mathrm{~mm})$, flat, steel springs on which 4 strain gages are glued. The height of springs is $70 \mathrm{~mm}$ and their width is $5 \mathrm{~mm}$. In order to precisely measure the force, which is applied on microwires the strain gage bridge is used. The force measurement module was calibrated using precise weights. The precision of the force measurement is equal to $0.1 \mathrm{mN}$. The second stage, which is mounted on 4 thicker, flat springs, is 
used as an actuator, which pulls the investigated microwire. Before the experiment, it is moved toward the measurement stage by the precise micrometric screw. The tension is then applied by releasing the screw. The distance is not measured.

After the experiment, when the microwire had been broken, the contact area between the copper and the ceramic particle was determined by the optical microscope and SEM images of the top of the two ends of the broken wire. The simple, dedicated computer program was used to measure the area of the complex shape created manually in the photo of the broken wire's end. Finally, the interface strength was determined according to the following equation:

$\sigma=\frac{F_{\mathrm{A}}}{S}$

where $F_{\mathrm{A}}$ stands for the adhesion force between a ceramic particle and the metal matrix and $S$ for the area of the interface.

\section{Results and Discussion}

In this paper, two different MMC samples were investigated: $\mathrm{Cu}-\mathrm{Al}_{2} \mathrm{O}_{3}$ with fine ceramic particles $(3 \mu \mathrm{m})$ and $\mathrm{Cu}-\mathrm{Al}_{2} \mathrm{O}_{3}$ with coarse ceramic particles $(180 \mu \mathrm{m})$. Firstly, the microstructure of the obtained composites materials was determined. The SEM images are presented in Fig. 3. In addition, the EDS surface analysis of the distribution of elements was performed and the resultant images can be found in Fig. 4. The SEM examination has revealed a homogeneous distribution of the ceramic phase in the composite. A good quality bonding (adhesion type) was observed between the copper matrix and the ceramic reinforcement, especially for the samples made with the coarse alumina powder. The STEM observation and the linear elements distribution were performed for microstructural investigations (Fig. 5) of the interface. They showed a clean ceramic-metal boundary and no evidence of the presence of the third phase. However, in both cases of $\mathrm{Cu}-\mathrm{Al}_{2} \mathrm{O}_{3}$ composites locally some amounts of $\mathrm{CuO}_{x}$ phase were observed.

The densities of the obtained composites, together with their hardness and bending test results, are collected in Table 1. The measurements showed that the densities of $\mathrm{Cu}-\mathrm{Al}_{2} \mathrm{O}_{3}$ composites were close to theoretical values. In both cases, the porosity was about $3 \%$. The resulting density values of composites are much higher than in the case of composites in which aluminum oxide $\alpha$ form is used as ceramic phase (density of $\mathrm{Cu}$ $5 \% \alpha \mathrm{Al}_{2} \mathrm{O}_{3}$ is usually $94 \%$ ) (Ref 13 ). The usage of electrocorundum as a reinforcing phase resulted in an increase in the density of composites from 94 to $97 \%$ values. Microstructural analyses indicated that the most of pores are located in the copper matrix. However, in the case of applying finer electrocorundum powder some pores between the individual particles were observed. The $3 \mu \mathrm{m} \mathrm{Al}_{2} \mathrm{O}_{3}$ particles form agglomerates in the matrix structure and they do not bond with each other in the conditions of sintering process $\left(1050^{\circ} \mathrm{C}\right)$ - Fig. 6. Such a phenomenon is not observed in the case of using coarser $\mathrm{Al}_{2} \mathrm{O}_{3}$ particles that can have significant influence on the quality of the bond. It should be noted that considerably higher hardness values were achieved for composite in which coarse powder of electrocorundum powder was used. It well corresponds to the density results of the composites.

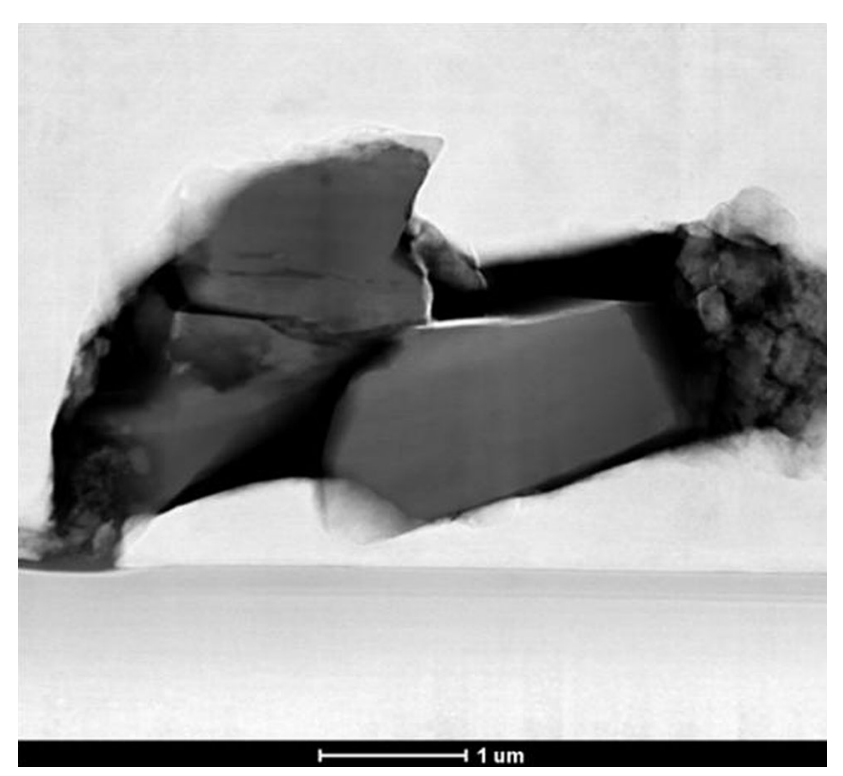

Fig. 6 TEM image of agglomerates of fine $\mathrm{Al}_{2} \mathrm{O}_{3}$ particles in copper matrix composites

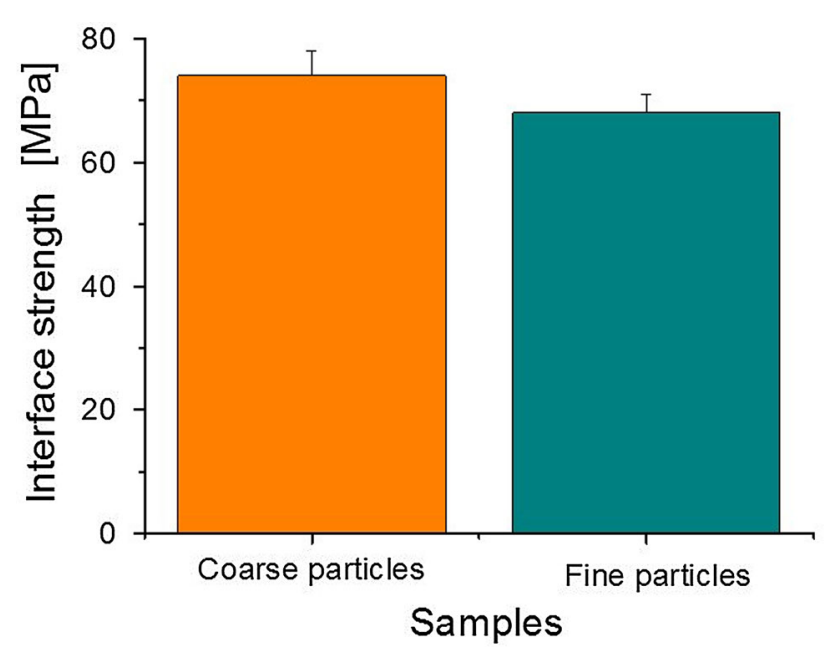

Fig. 7 The results of interface strength depending on the size of reinforcement particles

Table 1 Density and hardness of the $\mathrm{Cu}-\mathrm{Al}_{2} \mathrm{O}_{3}$ composites

\begin{tabular}{lcccc}
\hline Composite material & Measured density, $\mathbf{g} / \mathbf{c m}^{\mathbf{3}}$ & Relative density, \% & Hardness HV1 & Bending strength, MPa \\
\hline $\mathrm{Cu}-\mathrm{Al}_{2} \mathrm{O}_{3}$ fine $(3 \mu \mathrm{m})$ & 8.35 & 96.2 & $54.7 \pm 3.4$ & $289.6 \pm 1.9$ \\
$\mathrm{Cu}-\mathrm{Al}_{2} \mathrm{O}_{3}$ coarse $(180 \mu \mathrm{m})$ & 8.41 & 96.9 & $60.2 \pm 0.4$ & $202.1 \pm 4.5$ \\
\hline
\end{tabular}



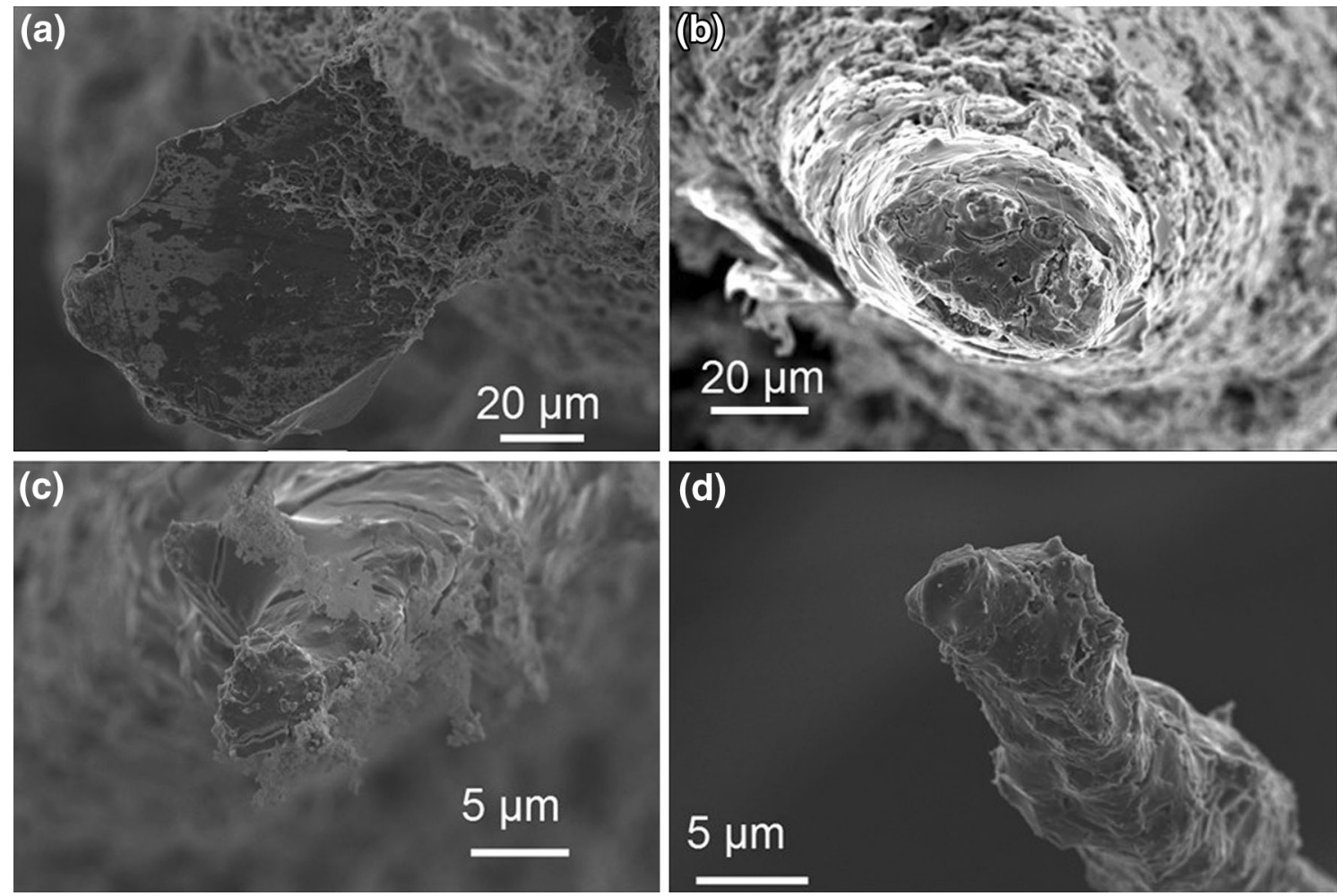

Fig. 8 Nanowires after the tensile test. $(a, b)$ coarse particle $(c, d)$ fine particle. The SEM micrographs were used to estimate the contact area in the interface

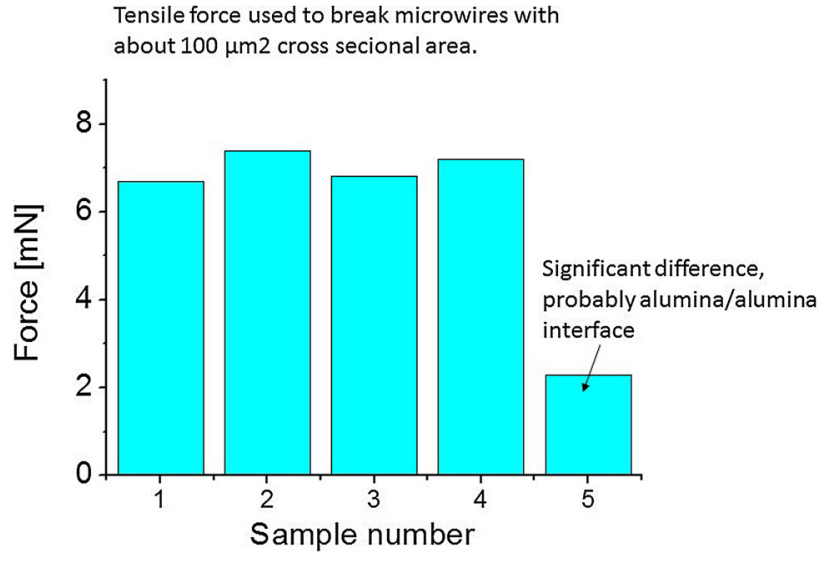

Fig. 9 Much lower ultimate tensile force is needed to break the ceramic/ceramic interface

The results of the interface strength evaluation for both samples are shown in Fig. 7. The interface strength is higher for the sample with coarse particles and is equal to $74 \pm 4 \mathrm{MPa}$ in this case. On the other hand, it is equal to $68 \pm 3 \mathrm{MPa}$ for the sample with fine ceramic particles. It is worth to note that the value of the interface strength is the average determined from 10 measurements for each sample. The measurement error is determined from a standard deviation of the experiment's results and the inaccuracy of contact area evaluation. Although the particles are of irregular shape, the results are repetitive (low standard deviation) because we have taken into consideration only the microwires in which the interface was relatively flat. It could be assumed then that the normal stress (tension) is dominant. It is worth to note that the tensile strengths of copper and alumina are equal to about 220 and $250 \mathrm{MPa}$, respectively (Ref 14). Hence, the wires break exactly at the interface. The detailed discussion of precise evaluation of the interface strength is discussed in Ref 12. The difference between fine and coarse particles may be explained by the SEM and TEM micrographs. The higher quality bonding was observed for the coarse particles. As it was mentioned before, it is due to the fact that in the case of finer particles there may be pores at the interface (Fig. 8).

Not only the $\mathrm{Cu}$ /alumina interface but also the adhesion between alumna particles can be investigated. The fine ceramic particles may agglomerate and the bonding between them is very weak. It is difficult to ascertain before the tensile test, by microscopic imaging, if the investigated microwire contains single particle or agglomerate of two or more of them. Even after the tensile test, it is not always possible due to the fact that the particles may totally debond and get separated from the microwire. However, due to the fact that the adhesion between ceramic particles is significantly lower than the adhesion between $\mathrm{Cu}$ and alumina, it can be assumed that the results which are significantly lower than the average results are achieved for ceramic-ceramic interface (Fig. 9). According to this assumption, it is possible to estimate the ceramic-ceramic interface strength to be equal to approximately $20 \mathrm{MPa}$. Regrettably, the precise value cannot be determined because the interface geometry in this case is always complicated-it is difficult to measure the contact area and the stress state is much more complicated than during the simple tension of the flat interface.

It should be noted that the measurement of the interface strength was possible only due to the fact that the microwires in 
both cases break usually exactly at the interface (Fig. 8). Hence, in these cases the adhesive force between metal matrix and ceramic particles is lower than the cohesive forces in copper and in aluminum oxide. On the other hand, in Ref 15, 16 it was observed that the particles in composites containing a high volume fraction of reinforcement are the weakest part of the composite. It confirms that the production technology and the metal-to-ceramic ratio play an essential role in the metal matrix composite failure mechanism.

\section{Conclusion}

It is well known that the type and strength of the metalceramic interface has a large influence on the mechanical properties of the bulk composite. The manufacturing process of copper-based composites reinforced with electrocorundum $\left(\mathrm{Al}_{2} \mathrm{O}_{3}\right)$ particles of significantly different granulation (fine $3 \mu \mathrm{m}$ and coarse $180 \mu \mathrm{m}$ ) was developed.

On the basis of the presented results following conclusion can be drawn:

- It is possible to obtain good quality $\mathrm{Cu}-\mathrm{Al}_{2} \mathrm{O}_{3}$ composites with the uniform distribution of reinforcement using hot pressing method (HP).

- A good quality bonding (adhesion type) was observed between the copper matrix and the ceramic reinforcement, especially for the samples made with the coarse alumina powder. TEM analyses confirmed clear interface at the metal/ceramic boundary. However, the same local presence of $\mathrm{CuO}_{x}$ phase was observed.

- It is possible to limit intergranular porosity in the ceramic phase by using coarse $\mathrm{Al}_{2} \mathrm{O}_{3}$ in copper-based composites, thus contributing to improve mechanical properties of these materials.

The size of the ceramic particles in MMCs can influence the mechanical properties of the interface between particles and matrix. The tensile tests of microwires made of copper matrix composites reinforced with $\mathrm{Al}_{2} \mathrm{O}_{3}$ particles with two different particle sizes show that in the case of smaller particles the interface is weaker.

\section{Acknowledgment}

The results presented in this paper have been obtained within the framework of the projects funded by the National Science Centre, decision number DEC-2014/13/N/ST8/00080 (PRELUDIUM) 2015-2017 and DEC-2012/07/N/ST8/03297 (PRELUDIUM).

\section{Open Access}

This article is distributed under the terms of the Creative Commons Attribution 4.0 International License (http://creativecommons.org/ licenses/by/4.0/), which permits unrestricted use, distribution, and reproduction in any medium, provided you give appropriate credit to the original author(s) and the source, provide a link to the Creative Commons license, and indicate if changes were made.

\section{References}

1. R.M. German, Sintering-Theory And Practice, Powder Metall., 1996, 39, p 260-261

2. J.W. Kaczmar, K. Pietrzak, and W. Wlosinski, The Production and Application of Metal Matrix Composite Materials, J. Mater. Process. Technol., 2000, 106, p 58-67

3. P. Franke, C. Heintze, F. Bergner, and T. Weissgaerber, Mechanical Properties of Spark Plasma Sintered Fe-Cr Compacts Strengthened by Nanodispersed Yttria Particles, Mater. Test., 2010, 52, p 133-138

4. M. Chmielewski, S. Nosewicz, K. Pietrzak, J. Rojek, A. Strojny-Nedza, S. Mackiewicz, and J. Dutkiewicz, Sintering Behavior and Mechanical Properties of NiAl, $\mathrm{Al}_{2} \mathrm{O}_{3}$, and $\mathrm{NiAl}-\mathrm{Al}_{2} \mathrm{O}_{3}$ Composites, J. Mater. Eng. Perform., 2014, 23, p 3875-3886

5. W. Weglewski, M. Basista, A. Manescu, M. Chmielewski, K. Pietrzak, and T. Schubert, Effect of Grain Size on Thermal Residual Stresses and Damage in Sintered Chromium-Alumina Composites: Measurement and Modeling, Compos. Part B, 2014, 67, p 119-124

6. A. Mortensen and J. Llorca, Metal Matrix Composites, Annu. Rev. Mater. Res., 2010, 40(40), p 243-270

7. W. Olesinska, D. Kalinski, M. Chmielewski, R. Diduszko, and W.K. Wlosinski, Influence of Titanium on the Formation of a "Barrier" Layer During Joining an AIN Ceramic with Copper by the CDB Technique, J. Mater. Sci., 2006, 17, p 781-788

8. M.W. Finnis, The Theory of Metal-Ceramic Interfaces, J. Phys., 1996, 8, p 5811-5836

9. J.T.M. De Hosson and B.J. Kooi, Metal/Ceramic Interfaces: A Microscopic Analysis, Surf. Interface Anal., 2001, 31, p 637-658

10. Y.M. Shabana, B.L. Karihaloo, H.X. Zhu, and S. Kulasegaram, Influence of Processing Defects on the Measured Properties of $\mathrm{Cu}$ $\mathrm{Al}_{2} \mathrm{O}_{3}$ Composites: A Forensic Investigation, Compos. Part A, 2013, 46, p $140-146$

11. A. Fathy and O. El-Kady, Thermal Expansion and Thermal Conductivity Characteristics of $\mathrm{Cu}-\mathrm{Al}_{2} \mathrm{O}_{3}$ Nanocomposites, Mater. Des., 2013, 46, p 355-359

12. D.M. Jarzabek, M. Chmielewski, and T. Wojciechowski, The Measurement of the Adhesion Force Between Ceramic Particles and Metal Matrix in Ceramic Reinforced-Metal Matrix Composites, Composites Part A, 2015, 76, p 124-130

13. A. Strojny-Nedza and K. Pietrzak, Processing, Microstructure and Properties of Different Method Obtained $\mathrm{Cu}-\mathrm{Al}_{2} \mathrm{O}_{3}$ Composites, Arch. Metall. Mater., 2014, 59, p 1301-1306

14. J.F. Shackelford and W. Alexander, CRC Materials Science and Engineering Handbook, 3rd ed., CRC Press, Boca Raton, 2000

15. A. Hauert, A. Rossoll, and A. Mortensen, Ductile-to-Brittle Transition in Tensile Failure of Particle-Reinforced Metals, J. Mech. Phys. Solids, 2009, 57, p 473-499

16. A. Hauert, A. Rossoll, and A. Mortensen, Particle Fracture in HighVolume-Fraction Ceramic-Reinforced Metals: Governing Parameters and Implications for Composite Failure, J. Mech. Phys. Solids, 2009, 57, p 1781-1800 